\title{
Diagnostics of DNA fragmentation in human spermatozoa: Are sperm chromatin structure analysis and sperm chromatin dispersion tests (SCD-HaloSpermG2 (R)) comparable?
}

Susanne Liffner, Isabelle Pehrson, Laura Garcia-Calvo, Elisabeth Nedstrand, Stefan Zalavary, Mats Hammar, Heriberto Rodriguez-Martinez and Manuel AlvarezRodriguez

The self-archived postprint version of this journal article is available at Linköping University Institutional Repository (DiVA):

http:// urn.kb.se/ resolve?urn=urn:nbn:se:liu:diva-159708

N.B.: When citing this work, cite the original publication.

Liffner, S., Pehrson, I., Garcia-Calvo, L., Nedstrand, E., Zalavary, S., Hammar, M., RodriguezMartinez, H., Alvarez-Rodriguez, M., (2019), Diagnostics of DNA fragmentation in human spermatozoa: Are sperm chromatin structure analysis and sperm chromatin dispersion tests (SCDHaloSpermG2 (R)) comparable?, Andrologia, 51(8), e13316. https:// doi.org/ 10.1111/and.13316

Original publication available at:

https:// doi.org/ 10.1111/ and.13316

Copyright: Wiley (12 months)

http:// eu.wiley.com/WileyCDA/ 
1 Diagnostics of DNA fragmentation in human spermatozoa: are Sperm Chromatin

2 Structure Analysis (SCSA) and Sperm Chromatin Dispersion tests (SCD-

$3 \quad$ HaloSpermG ${ }^{\circledR}$ ) comparable?

4

\section{Running Head: Sperm DNA fragmentation in idiopathic infertility}

S. Liffner, I. Pehrson, L. García-Calvo, E. Nedstrand, S. Zalavary, M. Hammar, H.

Rodríguez-Martínez, M. Álvarez-Rodríguez*

${ }^{a}$ Linköping University, Department of Clinical and Experimental Medicine (IKE), Obstetrics and Gynaecology, Linköping, SE-58183, Sweden.

*corresponding author: manuel.alvarez-rodriguez@liu.se

Men affected with idiopathic infertility often display basic spermiogramme values similar to fertile individuals, questioning the diagnostic impact of the WHO-thresholds used. This study explored sperm DNA fragmentation in single ejaculates from 14 fertile donors and 42 patients with idiopathic infertility providing semen for assisted reproductive techniques (ART) in a University fertility clinic. Each ejaculate were simultaneously studied for sperm DNA fragmentation by the flow cytometer-based Sperm Chromatin Structure Analysis (SCSA) and the new light-microscopy-based Sperm Chromatin Dispersion assay (SCD-HaloSpermG2®), before and after sperm selection for IVF with a colloid discontinuous gradient. The WHO-semen variables did not differ between groups, but DNA fragmentation after SCSA (DFI) or SCD (SDF) was significantly $(\mathrm{p}<0.05)$ higher in patients (DFI: $40.2 \% \pm 3.0$ vs. SDF: $40.3 \% \pm 1.4)$ than in fertile donors (DFI: $17.1 \% \pm 2.1$ vs. SDF: $20.9 \% \pm 2.5$ ). Sperm selection led to lower proportions of DNA-fragmented spermatozoa (DFI: $11.9 \pm 1.7$ vs. SCD: $10.0 \pm 0.9$, $\mathrm{p}<0.05)$. The techniques output correlated highly and significantly ( $\mathrm{r} 2=0.82)$. DNA fragmentation is confirmed as a relevant variable for scrutinizing patients with idiopathic infertility, beyond the evidently insufficient WHO-semen analyses. Since both techniques yielded similar results, the reduced necessity of complex equipment when running SCD ought to be considered for a clinical setting. 
Involuntary childlessness affects at present $\sim 90$ million couples worldwide, i.e. one out of seven couples (one out of four in Western countries) ought to seek diagnosis and eventual alleviating treatment via assisted reproductive techniques (ART) (Boivin, Bunting, Collins \& Nygren, 2007; Inhorn \& Patrizio, 2015). Human infertility is a complex condition, caused by anomalies or dysfunctions of either one of the partners, couple-related, or idiopathic (unknown etiology) (World Health Organization [WHO], 2010). Women age is a major risk factor (Fritz \& Jindal, 2018; Shirasuna \& Iwata 2017), with fertility even after IVF dropping below $30 \%$ already by 35 years of age (QIVF, 2018). Male subfertility at similar age intervals is thought to be predisposed/caused by several factors all leading to low sperm count, sperm dysfunction, or both (Levine et al., 2017; Mazur \& Lipshultz, 2018).

Human ejaculates collected for diagnostics and preparation for assisted reproductive parameters (WHO, 2010). These analyses, based on measurements of sperm concentration, motility and morphology are difficult to standardize among different laboratories (Pacey, 2010), and thus thresholds have been agreed by WHO (2010). Unfortunately, many men with results within "acceptable limits" remain diagnosed as idiopathically infertile even when using ART, i.e. no clear cause of the infertility has been found in either the women or the man (Pan, Hockenberry, Kirby \& Lipshultz, 2018). This indicates that sperm dysfunction is not fully diagnosed by the WHOrecommended methods, which are unable to determine neither the potential fertilizing capacity nor provide prognosis of the (in)-fertility potential of the couple (Agarwal, 
60 Use of in vitro fertilization (IVF) and the increasing use of forced fertilization via intra-

61 cytoplasmic sperm injection (ICSI) have undoubtedly ameliorated the condition of

62 childlessness. The procedures are, however, symptomatic and do not provide diagnosis

63 or specific treatment for the underlying pathologies. Moreover, their effectiveness has

64 remained unchanged over the past 15 years; with $\sim 30 \%$ of treatments resulting in birth

65 (Q-IVF, 2018). Such stagnation of the results requires increasing our knowledge on the

66 handling of semen, since both ARTs differ dramatically from the process of natural

67 conception. This is particularly true regarding use of non-ejaculated spermatozoa, ICSI

68 after testicular sperm extraction (elongated spermatids), or the unnatural mixing of

69 ejaculate fractions and later removal of the seminal plasma (SP).

71 A damaged sperm chromatin, including a fragmented DNA, may impair the capability 72 of the spermatozoa to fertilize. The first human clinical study showing a high 73 correlation between sperm DNA fragmentation and pregnancy outcomes was done in 74 an in vivo fertility study on 402 semen samples from 165 presumably fertile couples over 12 menstrual cycles (Evenson et al., 1999). The SCSA data from the male partners of 73 couples (group 1) achieving pregnancy during months 1-3 differed significantly from those of 40 couples (group 3) achieving pregnancy in months $4-12(\mathrm{P}<0.01)$ and those of male partners of 32 couples (group 5) not achieving pregnancy $(\mathrm{P}<0.001)$.

79 Group 2 contained couples who had a miscarriage. Based on logistic regression, the $\%$ DFI was the best predictor for whether a couple would not achieve a pregnancy.

81 Some $84 \%$ of males in group 1 had $\%$ DFI $<15 \%$, while no couples became pregnant in 82 group 1 with $>30 \%$. It has also been shown that DNA fragmentation decrease the 83 success of IVF (Wdowiak, Bakalchuk \& Bakalchuk, 2015) or ICSI (Avendaño, 
Franchi, Duran \& Oehninger, 2010), cause pregnancy loss (Brahem et al., 2011; Carlini et al., 2017; Osman, Alsomait, Seshadri, El-Toukhy \& Khalaf, 2015), and even reduce the health of the offspring (Coughlan et al., 2015; Jin et al., 2015; Simon et al., 2013; Virro, Larson-Cook \& Evenson, 2004). DNA fragmentation causes these effects often in relation to oocyte quality, suggesting a greater impact when ART is applied (Meseguer et al., 2011). Determination of DNA fragmentation in spermatozoa may thus be a relevant, complementary sperm parameter to reinforce current sperm analyses (Agarwal, Majzoub, Esteves, Ko, Ramasamy \& Zini, 2016b; Evgeni, Charalabopoulos \& Asimakopoulos, 2014; Giwercman et al., 2010; Kim, 2018; Lewis, 2015; Malić Vončina et al., 2016); particularly when ART is used (Bounartzi et al., 2016; Bungum et al., 2007; Yilmaz et al., 2010). Most interesting is the determination of sperm DNA fragmentation in cases of men diagnosed with idiopathic infertility, where semen variables are within "normal” limits (Bareh et al., 2016; Oleszczuk, Augustinsson, Bayat, Giwercman \& Bungum, 2013; Santi, Spaggiari \& Simoni, 2018).

Sperm DNA fragmentation has been evaluated with different techniques (Chohan, Griffin, Lafromboise, De Jonge \& Carrell, 2006; Kim, 2018; Panner Selvam \& Agarwal, 2018). Among these, the most popular for screening purposes is the sperm chromatin structure assay (SCSA), a 30-year old flow-cytometry/specific softwarelinked methodology with high repeatability and low variation (1-3\%) (Evenson, 2017); but requires specialized technicians for running it. Another technique with increasing popularity is the commercially available new kit for the sperm chromatin dispersion testing (SCD, HaloSpermG2 ${ }^{\circledR}$ ) (Zeqiraj et al., 2018). The SCD has high reproducibility $(<3 \%)$, does not require complex instruments becoming simpler and quick to run (Fernández et al., 2003). For each technique, clinical thresholds for the acceptable 
112 The aim of the present study was to explore the status of DNA fragmentation in WHO-

113 normozoospermic fertile men (sperm donors) and male partners of couples diagnosed

114 with idiopathic infertility; both providing semen for ART at a University fertility clinic.

115 The SCSA and SCD (HaloSpermG $2^{\circledR}$ ) tests were compared on spermatozoa prior to 116 and after a colloid gradient sperm selection. proportion of spermatozoa with DNA fragmentation have been established, $30 \%$ for the SCSA (Evenson, 2017) and 26\% for SCD (Wiweko \& Utami, 2017).

$$
\text { and after a colloid gradient sperm selection. }
$$

\section{Materials and Methods}

\subsection{Ethical approval}

Ethical permissions were approved by the regional Ethical Committee in Linköping (EPN-Linköping, Dnr 2010/398-31; Dnr 2013/103-31; Dnr 2013/344-32 and 2015/38731), including detailed patient information for individual written consent.

\subsection{Reagents and media}

All reagents were obtained from Sigma-Aldrich (Sweden), unless otherwise stated. HaloSpermG $2^{\circledR}$ was pursued from Hallotech DNA S.L. (Madrid, Spain).

\subsection{Study design and patient population}

This is a case series study where the population under study was a cohort of semen donors $(14$, control) or patients $(n=42)$ undergoing infertility investigation and/or ART-treatment (IVF) at the referral Reproduction Medicine Centre (RMC), Linköping University Hospital, Linköping, Sweden between October 2016 and October 2017. All subjects gave written informed consent for participation. The semen donors were fertile 
133 individuals (mean age 39.7 years), normozoospermic and with documented fertility.

134 The patients (mean age 33.2 years) were partners in an infertile couple who, after more

135 than one year of unprotected intercourse not leading to pregnancy, were andrologically

136 investigated, classified as affected by idiopathic infertility, and were pending ART by

137 IVF/ICSI. The diagnosis of idiopathic infertility (unexplained infertility) was based on

138 the following criteria: one year of unprotected intercourse without pregnancy,

139 unremarkable andrological story (no cryptorchidism, no genetic abnormalities, no

140 cancer treatment (radiation or chemotherapy), no drug/alcohol/medicine abuse, high

141 (>30) body mass index, or other iatrogenic factors), normal volume (>1.5 mL), sperm

142 concentration $\left(>15 \times 10^{6}\right.$ spermatozoa $\left./ \mathrm{mL}\right)$ or total sperm number $\left(>39 \times 10^{6}\right.$

143 spermatozoa), sperm motility ( $\geq 32 \%$ progressively motile spermatozoa), $>4 \%$ of

144 morphologically normal spermatozoa (WHO, 2010) and absence of leukospermia.

145 Moreover, absence of female factors in the partner (anovulation, tubal factor,

146 endometriosis).

$147 \quad 2.4$ Semen samples

148 Ejaculates (as bulk) were collected by masturbation after a recommended 2-5-day 149 abstinence period (WHO, 2010), either at the clinic or at home (when deliverable within

$150120 \mathrm{~min}$ of ejaculation). All ejaculates, one per individual, were coded. Following

151 routine assessment of sperm numbers and motility (see below), a $50 \mu \mathrm{L}$-semen aliquot

152 was centrifuged $\left(10,000 \times \mathrm{g}\right.$ at $5{ }^{\circ} \mathrm{C}$ for $\left.10 \mathrm{~min}\right)$ and the resulting sperm pellet extended

153 in TNE-buffer (Trizma hydrochloride $(10 \mathrm{mM}), \mathrm{NaCl}(150 \mathrm{mM})$, EDTA $(1 \mathrm{mM}))$ to

$1542 \times 10^{6}$ spermatozoa $/ \mathrm{mL}$ and frozen at $-80^{\circ} \mathrm{C}$ until analysed for DNA fragmentation.

155 Two $\mathrm{mL}$ of the rest of the ejaculate was subjected to a two-step discontinuous colloid

156 gradient using $40 \%$ and $80 \%$ PureSperm ${ }^{\circledR}$ (Nidacon International AB, Gothenburg,

157 Sweden) following the manufacturer set-up. After centrifugation at $300 \mathrm{xg}$ at $\mathrm{rt}$ for 30 
min, the sperm pellet at the bottom of the tube was retrieved, extended in maintaining

159 media (G-IVF Plus, Vitrolife, Göteborg, Sweden) to be thereafter handled as above

160 (centrifuged $10,000 \mathrm{xg}-\mathrm{TNE}-80^{\circ} \mathrm{C}$ freezing) until analysis.

$161 \quad 2.5$ Sperm motility

162 Sperm concentration $\left(\times 10^{6}\right.$ sperm $\left./ \mathrm{mL}\right)$, motility $(\%)$ and velocity $(\mu \mathrm{m} / \mathrm{sec})$ and

163 proportions of progressive sperm motility were assessed using an upright Zeiss Axio

164 Scope A1 light microscope equipped with a $10 \times$ phase contrast objective (Carl Zeiss,

165 Stockholm, Sweden) connected via a CMOS camera (UEye, IDS Imaging

166 Development Systems GmbH, Obersulm, Germany) to a computer holding the

167 Qualisperm ${ }^{\mathrm{TM}}$ sperm analysis software (Biophos SA, Lausanne, Switzerland;

168 www.biophos.com). Semen droplets $\left(\sim 24 \times 10^{4}\right.$ sperm in $\left.10 \mu 1\right)$ were placed on a pre-

169 warmed Menzel-Gläser pre-cleaned microscope slide (size: $76 \times 26 \mathrm{~mm}$; ThermoFisher

170 Scientific, Waltham, MA, USA) covered by a pre-warmed coverslip (size: $18 \times 18 \mathrm{~mm}$;

171 VWR, Stockholm, Sweden), on a thermal plate (Temp Controller 2000-2, Pecon

$172 \mathrm{GmbH}$, Erbach, Germany) kept at $38^{\circ} \mathrm{C}$.

$173 \quad 2.6$ DNA fragmentation analyses

174 Sperm DNA fragmentation was analysed using two different techniques (SCSA and

175 HaloSpermG $\left.2^{\circledR}\right)$, following thawing in a water bath $\left(37^{\circ} \mathrm{C}\right)$. Samples were kept

176 thereafter on an ice bed until analysis. Each measurement was replicated twice for each

177 method.

178 Sperm Chromatin Structure Analysis (SCSA)

179 Working solutions

180 TNE: Tris-HCl 10 mM, NaCl 150 mM and EDTA 1 mM; pH 7.4.

181 Acid detergent $(A C): \mathrm{NaCl} 150 \mathrm{mM}$, Triton X-100 0.1\% v/v and $\mathrm{HCl} 80 \mathrm{mM}$. 
Acridine orange (AO) working solution: Citric acid $33.4 \mathrm{mM}, \mathrm{Na}_{2} \mathrm{HPO}_{4} 132.3 \mathrm{mM}$, $\mathrm{NaCl} 150$ mM, EDTA 1mM, AO 6 mg/L; pH 6.

\section{Procedure}

The SCSA is based on the phenomenon that a $30 \mathrm{sec}$ treatment with $\mathrm{pH} 1.2$ buffer denatures the DNA at the sites of single- or double-strand breaks, whereas normal double-stranded DNA remains intact. The spermatozoa are thereafter stained with the fluorescent DNA dye acridine orange, which differentially stains double- and singlestranded DNA. Sperm chromatin damage is quantified using flow cytometry measurements of the metachromatic shift of AO after blue light excitation, where the intact (double-stranded) DNA emits green fluorescence while the denatured (singlestranded) DNA emits red fluorescence. This shift is captured as fluorescence intensity cytogram patterns. The extent of DNA denaturation is expressed as DNA Fragmentation Index (DFI), which is the ratio of red (level of denatured DNA) to total fluorescence intensity (the total DNA). The SCSA procedure protocol followed the description of Evenson (Evenson, Larson \& Jost, 2002; Evenson, 2013). In brief, 400 $\mu \mathrm{L}$ of $\mathrm{AC}$ solution were added to $200 \mu \mathrm{L}$ of standard sample (mixed samples with high heterogeneity) in a pre-cooled cytometer tube. After exactly $30 \mathrm{sec}, 1.2 \mathrm{~mL}$ of AO staining were added. The FL1-H $(500 \pm 5)$ and FL3-H $(130 \pm 5)$ were adjusted to thereafter proceed with all the donor/patient samples to be analysed at one time, without modifying the setting established after the standard sample. Sperm suspensions were analysed in duplicate in a Gallios ${ }^{\mathrm{TM}}$ flow cytometer (Beckman Coulter, Bromma, Sweden) equipped with standard optics: a violet laser $(405 \mathrm{~nm})$ with 2 colours, argon laser $(488 \mathrm{~nm})$ with 5 colours, and a HeNe-laser $(633 \mathrm{~nm})$ with 3 colours. The filter configuration was as follows: Blue: FL1 550SP 525BP and FL3 655SP 620/30. The instrument was controlled via the Navios software (Beckman Coulter, Bromma, 
207 Sweden). Analyses of acquired data were performed using the Kaluza software

208 (Beckman Coulter, Bromma, Sweden) on a separate PC. In all cases, 5,000 events were 209 assessed per sample, with a flow rate of 200-250 cells/sec. After further calculations of 210 the raw.fcs data in R-enviroment (package rflowcyt - Bioconductor), to obtain both $211 \%$ DFI (DNA Fragmentation Index above $24.5 \%$; DFI), ratio of red/red + green 212 fluorescence, where red is broken DNA and green is native DNA, and \%HDS (High 213 DNA Stainability; dependent of the green fluorescence; HDS), a measure (\%) of the 214 proportion of immature spermatozoa having defects in the histone-to-protamine 215 transition, which normally occurs during sperm maturation in the epididymis.

\section{Sperm Chromatin Dispersion assay (SCD, HaloSperm G2 ${ }^{\circledR}$ )}

217 Sperm DNA fragmentation was also examined with the commercial kit 218 HaloSpermG $2^{\circledR}$. This method is based on the characteristic halo formed when nuclear 219 proteins are removed/uncoiled by acid denaturation of the spermatozoa. Sperm nuclei 220 with severe DNA fragmentation forms either a very small halo or no halo at all (i.e. no 221 dispersion of DNA loops), while spermatozoa with little or without DNA fragmentation 222 forms a large halo (i.e. the DNA loops largely disperse). Following the manufacturer 223 protocol, $50 \mu \mathrm{L}$ of the thawed sperm sample were placed in a tube containing $100 \mu \mathrm{L}$ 224 of agarose (melted at $90{ }^{\circ} \mathrm{C}$ and subsequently placed for five minutes at $37^{\circ} \mathrm{C}$ ). A drop 225 of $8 \mu \mathrm{L}$ was deposited onto a super-coated glass slide, covered with a coverslip 226 (avoiding bubble formation), and the slide/s placed on a $4{ }^{\circ} \mathrm{C}$ cold surface for 5 min to 227 solidify the agarose with the spermatozoa embedded within. The coverslip was gently 228 removed and the glass slide kept horizontally to allow application of the denaturant 229 agent for $7 \mathrm{~min}$ at room temperature. After that, the denaturant was carefully removed 230 (without shaking) to apply the lysis solution for $20 \mathrm{~min}$. The slide was washed with 231 abundant distilled water for $5 \mathrm{~min}$ and then dehydrated with increasing concentrations 
232 of ethanol (70 and $100 \%$ ) each for $2 \mathrm{~min}$. The drops were then stained with eosine for

2337 min followed by thiazine staining for 7 additional minutes. Finally, the excess of

234 staining solutions was removed and the slides allowed to dry at room temperature.

235 Visualization was performed in an inverted bright field microscope (LEICA D100,

236 Stockholm, Sweden). A minimum of 200 spermatozoa per sample were scored at x400

237 magnification. In order to reduce bias, two persons counted the same sample.

238 Calculation of the percentage of spermatozoa with fragmented DNA (as SDF) was

239 performed dividing the number of fragmented + degraded spermatozoa by the total

240 number of spermatozoa counted $(\times 100)$. A positive control was run skipping the

241 addition of the denaturant agent, where all spermatozoa were shown with halo. A

242 negative control was run, where the lysis solution was skipped: all spermatozoa lacked 243 halo.

\subsection{Statistical analysis}

246 Statistical analysis, including calculation of coefficient of variation (CV; Standard 247 deviation/mean $\times 100)$ and confidence interval $(\mathrm{CI})$ at $95 \%$ confidence level, was 248 performed in R-package using linear mixed-effects models. Residuals were tested for 249 normality (Shapiro-Wilk test). The data of progression tests were normally distributed. 250 Percentage data were arcsin square-root transformed when necessary. Individual 251 samples were used as the grouping factor in the random part of the models. Results are 252 shown as means \pm standard deviation, unless otherwise stated. The Bland-Altman 253 procedure was performed in order to analyse the agreement between the two different 254 assays carried out. Pearson correlation (two-sided) was performed between different 255 measurement points and different analysed parameters. A significance statistical level 256 of $\mathrm{P}<0.05$ was used. 


\section{Results}

259 The conventional WHO-semen parameters did not statistically differ between the 260 idiopathic infertile patients and fertile donors. The coefficient of variation (CV) 261 between the replicate analyses was 3.6\% for the SCSA and $4.7 \%$ for the HaloSpermG2.

262 The proportions of spermatozoa with DNA fragmentation in fertile donors and patients 263 were similarly measured by either technique. For fertile semen donors, the Sperm 264 Chromatin Dispersion (SDF) was 20.9\% \pm 9.4 (range: $6.8-41.0 ; \mathrm{CV}=44.9 \%$; 95\% 265 confidence interval $(\mathrm{CI}=15.976,25.824)$ and the DNA fragmentation after SCSA (DFI) 266 was $17.1 \% \pm 7.8$ (range: $6.9-31.2 ; \mathrm{CV}=45.6 \% ; \mathrm{CI}=13.014,21.186$ ). The patients 267 depicted an SDF of $40.1 \% \pm 9.0$ (range: $24.6-59.6 ; \mathrm{CV}=22.4 \%$; $\mathrm{CI}=37.378,42.822$ ) 268 versus a DFI of $40.2 \% \pm 19.3$ (range: $2.3-80 ; \mathrm{CV}=48.0 \%$; CI [34.363, 46.037). Values 269 did not differ statistically within group (ns), but the fertile semen donors had 270 significantly $(\mathrm{p}<0.05)$ fewer spermatozoa with fragmented DNA measured with either 271 method than patients with a diagnosis of idiopathic infertility. After the spermatozoa 272 were selected by colloid discontinuous gradient in patients, their sperm motility 273 increased to $89.7 \pm 14.0 \%$ and sperm velocity to $43.4 \pm 11.9 \mu \mathrm{m} / \mathrm{sec}$ (Mean \pm SD) and 274 those depicting fragmented DNA were significantly fewer $(\mathrm{p}<0.05)(\mathrm{SDF}: 10.0 \% \pm 5.9$ $275(2.3 / 30.9))$ and DFI: $11.9 \pm 11.2(0.6 / 53.5))$ compared to the initial ejaculate, posing a 276 tendency $(\mathrm{p}>0.05)$ to reach fertile donor values.

278 Lower values of "High DNA Stainability" (HDS), a measure (\%) of the proportion of 279 immature spermatozoa having defects in the histone-to-protamine transition, were 280 found in samples from patients after the colloid discontinuous gradient $(6.7 \% \pm 4.6$ 
$281(2.4 / 22))$ compared to the initial ejaculates; either from patients $(13.2 \% \pm 10.3$

$282(1.6 / 42.2))$ or from fertile donors $(14.1 \% \pm 10.2(5.9 / 39.8))$.

284 Both the SDF parameter yielded by the SCD-assay $\left(\right.$ HaloSpermG2 $\left.{ }^{\circledR}\right)$ and that of the 285 SCSA assay (DFI) were positively and highly $(\mathrm{R}=0.82, \mathrm{p}<0.05)$ correlated in semen 286 donors as well as patients. These results were confirmed through analysis of a Bland287 Almand plot (FIGURE 1).

\section{Discussion}

290 The present study confirmed the value of both SCSA and SCD (HaloSpermG $2^{\circledR}$ ) to

291 determine sperm DNA fragmentation in semen with apparently similar WHO-standard

292 semen parameters. Men with these conventional semen values ought to be considered 293 normozoospermic, despite being either derived from fertility-proven semen donors or 294 from male partners of couples diagnosed with unexplained infertility. Irrespective of 295 the technique used, the infertile patients showed significantly higher DNA 296 fragmentation rates compared to fertile donors, well beyond values considered 297 clinically normal thresholds (Evenson, 2017; Wiweko \& Utami, 2017). To this point, 298 DNA fragmentation adds a diagnostic value for the screening of males diagnosed with 299 idiopathic infertility, beyond what is praxis during andrological routine evaluation.

301 Of major interest were the results of the correlations between the two techniques, 302 providing at hand that they were basically similar in disclosing DNA fragmentation 303 values in most paired samples. The SCSA is today the most commonly used testing 304 method for DNA fragmentation in clinical evaluations, measuring only single-stranded 
DNA fragments. The method is based on the higher vulnerability of DNA from

306 damaged spermatozoa to acid detergent denaturation, which enhances the binding of

307 acridine orange as an aggregate to the single-stranded DNA differentiating it from the

308 intact double-stranded DNA (Evenson et al., 2002). The parameter most commonly

309 followed is the DNA fragmentation index (DFI, \%) which indicates the relative number

310 of spermatozoa with DNA damage. Moreover, the SCSA provides a measure (\%) of

311 the proportion of immature spermatozoa having defects in the histone-to-protamine

312 transition, which normally occurs during sperm maturation in the epididymis, under the

313 acronym HDS (High DNA Stainability). Following both parameters, a clinical

314 prognosis for fertility after ART has been established, where a combination of DFI

315 higher than $30 \%$ and HDS higher than $15 \%$, would lead to fertilization failure, low

316 blastocyst development or no pregnancy (Evenson, 2017; Virro et al., 2004;). The

317 SCSA analyses large numbers of spermatozoa under short time, it has a high 318 reproducibility (1-3\% intra-assay variation (Evenson, 2017)), becoming statistically

319 robust, proven by a long-lasting use worldwide. However, it has disadvantages for 320 application in a clinical setting, since it requires technical know-how, handling specific 321 software and an expensive flow cytometry equipment.

323 The SCD assay has also been used for a long time (Fernández et al., 2003), being further 324 developed under time to attempt becoming an economical and management alternative 325 to SCSA (Feijó \& Esteves; 2014). As such, it has been adopted by many IVF clinics 326 since it is simple, quick, does not require expensive or complicated instruments and, 327 moreover, has high reproducibility ( $<3 \%$ intra-assay variation) (Panner Selvam \& 328 Agarwal, 2018; Zeqiraj et al., 2018). The CV for the reference sample and replicates 329 assayed in the present study were well within these values, confirming previous studies 
331 acid denaturation, which generates single-stranded DNA motifs from DNA breaks.

332 This acid detergent treatment causes uncoiling of nuclear proteins from the chromatin,

333 allowing the highly coiled intact DNA to expand and to form a halo over the sperm

334 head; the larger the halo, the less DNA damage present. The following lysis step in

$335 \mathrm{SCD}-\mathrm{HaloSpermG} 2^{\circledR}$ causes deproteinization of the chromatin which suppresses the

336 formation of a halo. The mechanism for this halo suppression is unknown but the

337 suppression of halo formation is not observed in spermatozoa with unfragmented DNA.

338 The major advantage of the method is the easiness to count spermatozoa with damaged

339 DNA (no halo/small halo) from the rest (large halos). However, even considering these

340 advantages, the periphery of the halo where low-density nucleoids are often located is

341 faint, and yields low-contrast images that can lead to errors since the halo border is

342 difficult to distinguish. Moreover, sometimes halos are not all in the same focal plane,

343 requiring the operator to be confident in managing the microscope during counting.

344 Lastly, contaminant cells other than spermatozoa can also produce halo and they must 345 be distinguished.

347 Several other methods can be used to determine DNA damage in spermatozoa (rev by 348 Rodriguez-Martinez, 2014), such as the terminal deoxynucleotidyl transferase349 mediated fluorescein-dUTP nick-end labelling (TUNEL), the acridine orange test 350 (AOT), the tritium-labelled 3H-actinomycin D (3H-AMD) incorporation assay, the in 351 situ nick translation (ISTN), the DNA breakage detection-fluorescence in-situ 352 hybridizations (DBD-FISH), and the single-cell gel electrophoresis assay (COMET) 353 including the variants of alkaline COMET and the neutral COMET, the latter with 354 specific threshold values for prediction of male infertility (Ribas-Maynou et al., 2013). 
Relevant for the newly available and hereby used HaloSpermG $2^{\circledR}$ is, moreover being

356 less cumbersome than some of the above listed methods or SCSA, is the inclusion of a 357 reduced acid detergent treatment step $(20 \mathrm{~min})$ as well as a lysis step that 358 reduces/eliminates false-positive counting.

360 In the present study, spermatozoa from patients diagnosed with idiopathic infertility 361 showed, despite having a routine spermiogramme within normal WHO-criteria limits, 362 an increased DNA fragmentation level, measured by two analytical techniques, 363 compared with fertile semen donors. Such increased levels would be one reason for a 364 decreased fertility, where a dysfunction at the chromatin level would not be detected 365 using conventional semen analyses. Fertile donors were all well under the threshold for 366 in vivo fertility determined for the analytical techniques (DFI: $17.1 \% \pm 8.0$; SDF: $20.9 \%$ $367 \pm 9.4$ ). The values did not differ statistically. Single ejaculates (one per person) were 368 examined in the present study, the rationale being that the exams for DNA 369 fragmentation were intended on semen that was aimed for IVF. The CV and 95\% 370 confidence intervals for DFI or SDF were similarly large for fertile semen donors and 371 infertile patients. The large CV would be caused by the use of single samples, 372 considering that the variation among ejaculates within individual was reported large, 373 irrespective of the number of ejaculates examined per person (Erenpreiss et al., 2006a).

374 The semen from the fertile donors used for IVF have led to live babies born (data not 375 shown). This might reinforce the value of a low DNA fragmentation rate for fertility. 376 Semen from the patients was also used for IVF, after a cleansing/selection procedure 377 based on a commercial discontinuous colloid gradient. The spermatozoa selected by the 378 procedure were also examined by SCSA and SCD, and levels of DNA fragmentation 379 were significantly decreased by the selection procedure, basically three-fold after the 
gradient. The proportion of spermatozoa after gradient selection with fragmented DNA

381 even reached levels below those registered in the normozoospermic semen donors. A 382 follow-up of the IVF-results for these patients revealed a lack of correlation between 383 DNA fragmentation level after the gradient with the rates of fertilization, blastocyst or 384 live births, with pregnancies-to-term being established even with significantly higher 385 DNA fragmentation values (not different neither for DFI nor SDF). Noteworthy, the 386 levels of DNA fragmentation for successful pregnancies-to-term were always below 387 the clinical threshold established for SCSA or SCD, e.g. $<24.5 \%$ (Mean \pm SD 388 ( $\min / \max ))$ : No pregnancy-to-term (DFI: $9.6 \% \pm 8.4(0.6-34.4)$ vs. SDF: $8.7 \% \pm 6.0$ $389((2.3-30.9))$ vs. pregnancy-to-term (DFI: $12.9 \% \pm 5.1(6.6-22.4)$ vs. SDF: $17.3 \% \pm$ 390 14.5(1.4-53.4)). Such results should be considered in the light of the restricted number 391 of individuals constituting the cohorts. Moreover, conflicting results have been 392 presented in the literature regarding the relationship of DNA fragmentation measured 393 by either technique and the various end-points measured: fertilization, blastocyst rate, 394 early pregnancy diagnosis, birth rate, or the possible complications that sometimes 395 occur (abortion, miscarriage, etc). Some studies praise the SCSA for their prognostic 396 value (Evenson et al., 2002; Evenson, 2017) while others do the same for the SCD 397 (Comhaire, Messiaen \& Decleer, 2018; Fernández, Cajigal, López-Fernández \& 398 Gosálvez, 2011; Pregl Breznik, Kovačič \& Vlaisavljević, 2013; Zheng et al., 2018). 399 Caution has been recommended when considering prognosis after IVF or ICSI using 400 solely DNA fragmentation (Anifandis et al., 2015; Cissen et al., 2016; Erenpreiss, 401 Spano, Erenpreis, Bungum \& Giwercman, 2006b; Zhang et al., 2015) particularly 402 when colloid gradients are used since other methods for sperm selection are more 403 valuable, as swim-up (Zandieh et al., 2018). 
The relevance of the present study is that both methods showed similar results, with a

406 relevant statistical correlation, and that the diagnostics was valuable, since a possible

407 explanation for the infertility among the participating patients could have been the high

408 proportion of spermatozoa with damaged DNA (Oguz et al., 2018). When their semen

409 was subjected to gradient selection the proportion of damaged spermatozoa decreased

410 and pregnancies-to-term were established. However, it should be considered that

411 gradient selection, although selecting for DNA intactness using the SCD-

412 HaloSpermG $2^{\circledR}$ assay does not seem to statistically correlate with pregnancy-to-term

413 after IVF (Comhaire et al., 2018; Zheng et al., 2018) or ICSI (Wang et al., 2014).

\section{Conclusion}

416 In conclusion, SCSA and SCD-HaloSpermG2 ${ }^{\circledR}$ are comparable techniques for 417 measuring sperm DNA fragmentation, with a logistic advantage for the latter if 418 intending application in a clinical setting. Further studies with larger cohorts are 419 warranted to confirm these results.

\section{Acknowledgements}

422 Marie Rubér and Alejandro Vicente-Carrillo, Linköping University are warmly

423 acknowledged for their kind assistance in the primary handling of ejaculates. The study 424 was supported by grants from ALF-Research (Region Östergötland, LIO-698951), 425 FORSS (Forskningsrådet i Sydöstra Sverige, Grant 473121 and Grant 745971), Lions 426 Forskningsfond (DNR LIU-2016-00641) and the Swedish Research Council FORMAS 427 (Grant 2017-00946), Stockholm, Sweden; including student grants for I.P. (Region 428 Östergötland, LIO-70460/802571/833121) and L.G-C (Formas). 
431 The authors declare no conflicts of interest to disclose.

432

\section{Authors' Contributions}

434 M.A-R., S.L., M.H. and H.R-M. designed the experiments. M.A-R., I.P., L.G-C. and 435 S.L. executed the experiments. M.A-R. performed analyses of data and wrote the first 436 draft of the manuscript. E.N. recruited patients. S.Z. secured semen samples. All 437 authors read, contributed and approved the final manuscript. M.A-R. and H.R-M. 438 secured funding. 


\section{References}

Agarwal, A., Cho, C.L., \& Esteves, S.C. (2016a). Should we evaluate and treat sperm DNA fragmentation? Current Opinion in Obstetrics and Gynecology, 28(3), 164171. https://doi.org/10.1097/GCO.0000000000000271

Agarwal, A., Majzoub, A., Esteves, S.C., Ko, E., Ramasamy, R., \& Zini, A. (2016b). Clinical utility of sperm DNA fragmentation testing: practice recommendations based on clinical scenarios. Translational Andrology and Urology, 5(6), 935-950. https://doi.org/10.21037/tau.2016.10.03

Anifandis, G., Bounartzi, T., Messini, C.I., Dafopoulos, K., Markandona, R., Sotiriou, V., \& Messinis, I.E. (2015). Sperm DNA fragmentation measured by Halosperm does not impact on embryo quality and ongoing pregnancy rates in IVF/ICSI treatments. Andrologia, 47(3), 295-302. https://doi.org/10.1111/and.12259

Avendaño C., Franchi A., Duran H., \& Oehninger S. (2010). DNA fragmentation of normal spermatozoa negatively impacts embryo quality and intracytoplasmic sperm injection outcome. Fertility and Sterility, 94(2), 549-557. https://doi.org/10.1016/j.fertnstert.2009.02.050

Bareh, G.M., Jacoby, E., Binkley, P., Chang, T.-C.A., Schenken, R.S., \& Robinson, R.D. (2016). Sperm deoxyribonucleic acid fragmentation assessment in normozoospermic male partners of couples with unexplained recurrent pregnancy loss: a prospective study. Fertility and Sterility, 105(2), 329-336.e1. https://doi.org/10.1016/j.fertnstert.2015.10.033

Boivin, J., Bunting, L., Collins, J.A., \& Nygren, K.G. (2007). International estimates of infertility prevalence and treatment-seeking: potential need and demand for infertility medical care. Human Reproduction, 22(6), 1506-1512. https://doi.org/10.1093/humrep/dem046

Bounartzi, T., Dafopoulos, K., Anifandis. G., Messini C.I., Koutsonikou, C., Kouris, V., \& Messinis, I.E. (2016). Pregnancy prediction by free sperm DNA and sperm DNA fragmentation in semen specimens of IVF/ICSI-ET patients. Human Fertility (Cambridge), 19(1), 56-62. https://doi.org/10.3109/14647273.2016.1157629

Brahem, S., Mehdi, M., Landolsi, H., Mougou, S., Elghezal, H., \& Saad, A. (2011). Semen parameters and sperm DNA fragmentation as causes of recurrent pregnancy loss. Urology, 78(4), 792-796. https://doi.org/10.1016/j.urology .2011.05.049

Bungum, M., Humaidan, P., Axmon, A., Spano, M., Bungum, L., Erenpreiss, J., \& Giwercman, A. (2007). Sperm DNA integrity assessment in prediction of assisted reproduction technology outcome. Human Reproduction, 22(1), 174-79. https://doi.org/10.1093/humrep/del326

Carlini, T., Paoli, D., Pelloni, M., Faja, F., Dal Lago, A., Lombardo, F., \& Gandini, L. (2017). Sperm DNA fragmentation in Italian couples with recurrent pregnancy loss. Reproductive Biomedicine Online, 34(1), 58-65. https://doi.org/10.1016/j.rbmo.2016.09.014

Chohan, K.R., Griffin, J.T., Lafromboise, M., De Jonge, C.J., \& Carrell, D.T. (2006). Comparison of chromatin assays for DNA fragmentation evaluation in human sperm. Journal of Andrology, 27(1), 53-59. https://doi.org/10.2164/jandrol.05068

Cissen, M., Wely, M.V., Scholten, I., Mansell, S., Bruin, J.P., Mol, B.W., \& Hamer, G. (2016). Measuring sperm DNA fragmentation and clinical outcomes of medically assisted reproduction: a systematic review and meta-analysis. PLoS ONE, 11(11), e0165125. https://doi.org/10.1371/journal.pone.0165125

Comhaire, F., Messiaen, A., \& Decleer, W. (2018). A mathematical model predicting the individual outcome of IVF through sperm-analysis: The role of the 
HaloSpermG2® DNA fragmentation test. Medical Hypotheses, 117, 50-53. https://doi.org/10.1016/j.mehy.2018.05.021

Coughlan, C., Clarke, H., Cutting, R., Saxton, J., Waite, S., Ledger, W., \& Pacey, A.A. (2015). Sperm DNA fragmentation, recurrent implantation failure and recurrent miscarriage. Asian Journal of Andrology, 17(4), 681-685. https://doi.org/10.4103/1008-682X.144946

Erenpreiss, J., Bungum, M., Spano, M., Elzanaty, S., Orbidans, J., \& Giwercman, A. (2006a). Intra-individual variation in sperm chromatin structure assay parameters in men from infertile couples: clinical implications. Human Reproduction, 21(8), 2061-2064. https://doi.org/10.1093/humrep/der328

Erenpreiss, J., Spano, M., Erenpreisa, J., Bungum, M., \& Giwercman, A. (2006b). Sperm chromatin structure and male fertility: biological and clinical aspects. Asian Journal of Andrology, 8(1), 11-29. https://doi.org/10.1111/j.17457262.2006.00112.x

Evenson D.P. (2013) Sperm Chromatin Structure Assay: In: Spermatogenesis: Methods and Protocols (Methods in Molecular Biology) Douglas Carell, Kenneth Aston, eds.) Humana Press

Evenson, D.P. (2017). Evaluation of sperm chromatin structure and DNA strand breaks is an important part of clinical male fertility assessment. Translational Andrology and Urology, 6(S4), S495-S500. https://doi.org/10.21037/tau.2017.07.20

Evenson, D.P., Jost, L.K., Zinaman, M.J., Clegg, E., Purvis, K., de Angelis \& Clausen, O.P. (1999). Utility of the sperm chromatin structure assay (SCSA) as a diagnostic and prognostic tool in the human fertility clinic. Human Reproduction, 14(4), 10391049. https://doi.org/10.1093/humrep/14.4.1039

Evenson, D.P., Larson, K.L., \& Jost, L.K. (2002). Sperm chromatin structure assay: its clinical use for detecting sperm DNA fragmentation in male infertility and comparisons with other techniques. Journal of Andrology, 23(1), 25-43. https://doi.org/10.1002/j.1939-4640.2002.tb02599.x

Evgeni, E., Charalabopoulos, K., \& Asimakopoulos, B. (2014). Human sperm DNA fragmentation and its correlation with conventional semen parameters. Journal of Reproduction and Infertility, 15(1), 2-14.

Feijó, C.M., \& Esteves, S.C. (2014). Diagnostic accuracy of sperm chromatin dispersion test to evaluate sperm deoxyribonucleic acid damage in men with unexplained infertility. Fertility and Sterility, 101(1), 58-63.e3. https://doi.org/10.1016/j.fertnstert.2013.09.002

Fernández, J.L., Cajigal, D., López-Fernández, C., \& Gosálvez, J. (2011). Assessing sperm DNA fragmentation with the sperm chromatin dispersion test. Methods in Molecular Biology, 682, 291-301. https://doi.org/10.1007/978-1-60327-409-8_21

Fernández, J.L., Muriel, L., Rivero, M.T., Goyanes, V., Vazquez, R., \& Alvarez, J.G. (2003). The sperm chromatin dispersion test: a simple method for the determination of sperm DNA fragmentation. Journal of Andrology, 24(1), 59-66. https://doi.org/10.1002/j.1939-4640.2003.tb02641.x

Fritz, R., \& Jindal, S. (2018). Reproductive aging and elective fertility preservation. Journal of Ovarian Research, 11(1), 66. https://doi.org/10.1186/s13048-018-0438-4

Giwercman, A., Lindstedt, L., Larsson, M., Bungum, M., Spano, M., Levine, R.J., \& Rylander, L. (2010). Sperm chromatin structure assay as an independent predictor of fertility in vivo: a case-control study. International Journal of Andrology, 33(1), e221-227. https://doi.org/ 10.1111/j.1365-2605.2009.00995.x 
Inhorn, M.C., \& Patrizio, P. (2015). Infertility around the globe: new thinking on gender, reproductive technologies and global movements in the 21 st century. Human Reproduction Update, 21(4), 411-426. https://doi.org/ 10.1093/humupd/dmv016

Jin, J., Pan, C., Fei, Q., Ni, W., Yang, X., Zhang, L., \& Huang, X. (2015). Effect of sperm DNA fragmentation on the clinical outcomes for in vitro fertilization and intracytoplasmic sperm injection in women with different ovarian reserves. Fertility and Sterility,103(4), 910-916. https://doi.org/10.1016/j.fertnstert.2015.01.014

Kim, G.Y. (2018) What should be done for men with sperm DNA fragmentation? Clinical and Experimental Reproductive Medicine, 45(3), 101-109. https://doi.org/10.5653/cerm.2018.45.3.101

Levine, H., Jørgensen, N., Martino-Andrade, A., Mendiola, J., Weksler-Derri, D., Mindlis, I., \& Swan, S.H. (2017). Temporal trends in sperm count: a systematic review and meta-regression analysis. Human Reproduction Update, 23(6), 646-659. https://doi.org/10.1093/humupd/dmx022

Lewis, S.E.M., John Aitken, R., Conner, S.J., Iuliis, G.D., Evenson, D.P., Henkel, R., $\&$ Gharagozloo, P. (2013). The impact of sperm DNA damage in assisted conception and beyond: recent advances in diagnosis and treatment. Reproductive Biomedicine Online, 27(4), 325-337. https://doi.org/10.1016/j.rbmo.2013.06.014

Lewis, S.E.M. (2015). Should sperm DNA fragmentation testing be included in the male infertility work-up? Reproductive Biomedicine Online, 31(2), 134-137. https://doi.org/10.1016/j.rbmo.2015.05.006

Malić Vončina, S., Golob, B., Ihan, A., Kopitar, A.N., Kolbezen, M., \& Zorn, B. (2016). Sperm DNA fragmentation and mitochondrial membrane potential combined are better for predicting natural conception than standard sperm parameters. Fertility and Sterility,105(3), 637-644.e1. https://doi.org/10.1016/j.fertnstert.2015.11.037

Mazur, D.J., \& Lipshultz, L.I. (2018). Infertility in the Aging Male. Current Urology Reports, 19(7), 54. https://doi.org/10.1007/s11934-018-0802-3

Meseguer, M., Santiso, R., Garrido, N., García-Herrero, S., Remohí, J., \& Fernandez, J.L. (2011). Effect of sperm DNA fragmentation on pregnancy outcome depends on oocyte quality. Fertility and Sterility, 95(1), 124-128. https://doi.org/10.1016/j.fertnstert.2010.05.055

Oguz, Y., Guler, I., Erdem, A., Mutlu, M.F., Gumuslu, S., Oktem, V. \& Erdem, M. (2018). The effect of swim-up and gradient sperm preparation techniques on deoxyribonucleic acid (DNA) fragmentation in subfertile patients. Journal of Assisted Reproduction and Genetics, 35(6), 1083-1089. https://doi.org/10.1007/s10815-018-1163-z

Oleszczuk, K., Augustinsson, L., Bayat, N., Giwercman, A., \& Bungum, M. (2013). Prevalence of high DNA fragmentation index in male partners of unexplained infertile couples. Andrology, 1(3), 357-360. https://doi.org/10.1111/j.20472927.2012.00041.x

Osman, A., Alsomait, H., Seshadri, S., El-Toukhy, T., \& Khalaf, Y. (2015). The effect of sperm DNA fragmentation on live birth rate after IVF or ICSI: a systematic review and meta-analysis. Reproductive Biomedicine Online, 30(2), 120-127. https://doi.org/10.1016/j.rbmo.2014.10.018

Pacey, A.A. (2010). Quality assurance and quality control in the laboratory andrology. Asian Journal of Andrology, 12(1), 21-25. https://doi.org/10.1038/aja.2009.16

Pan, M.M., Hockenberry, M.S., Kirby, E.W., \& Lipshultz, L.I. (2018). Male infertility diagnosis and treatment in the era of in vitro fertilization and intracytoplasmic sperm 
injection. Medical Clinics of North America, 102(2), 337-347. https://doi.org/10.1016/j.mcna.2017.10.008

Panner Selvam, M.K., \& Agarwal, A. (2018). A systematic review on sperm DNA fragmentation in male factor infertility: Laboratory assessment. Arab Journal of Urology, 16(1), 65-76. https://doi.org/10.1016/j.aju.2017.12.001

Pregl Breznik, B., Kovačič, B., \& Vlaisavljević, V. (2013). Are sperm DNA fragmentation, hyperactivation, and hyaluronan-binding ability predictive for fertilization and embryo development in in vitro fertilization and intracytoplasmic sperm injection? Fertility and Sterility, 99(5), 1233-1241. https://doi.org/10.1016/j.fertnstert.2012.11.048

Ribas-Maynou, J., García-Peiró, A., Fernández-Encinas, A., Abad, C., Amengual, M.J., Prada, E., Navarro, J. \& Benet, J. (2013). Comprehensive analysis of sperm DNA fragmentation by five different assays: TUNEL assay, SCSA, SCD test and alkaline and neutral Comet assay. Andrology. 1(5), 715-722. https://doi.org/10.1111/j.20472927.2013.00111.x.

Rodriguez-Martinez, H. (2014). Semen evaluation and handling: emerging techniques and future development. Pp 509-549, Ch 19 in P.J. Chenoweth and S. Lorton (eds.) Animal andrology: theory and applications, Cabi, Oxfordshire, UK (ISBN-10: 1780643160).

Q-IVF. http://www.ucr.uu.se/qivf (last access 2019-01-30).

Santi, D., Spaggiari, G., \& Simoni, M. (2018). Sperm DNA fragmentation index as a promising predictive tool for male infertility diagnosis and treatment management meta-analyses. Reproductive Biomedicine Online, 37(3), 315-326. https://doi.org/10.1016/j.rbmo.2018.06.023

Shirasuna, K., \& Iwata, H. (2017). Effect of aging on the female reproductive function. Contraception and Reproductive Medicine, 3, 2-23. https://doi.org/10.1186/s40834017-0050-9

Simon, L., Proutski, I., Stevenson, M., Jennings, D., McManus, J., Lutton, D., \& Lewis, S.E. (2013). Sperm DNA damage has a negative association with live-birth rates after IVF. Reproductive Biomedicine Online, 26(1), 68-78. https://doi.org/10.1016/j.rbmo.2012.09.019

Virro, M.R., Larson-Cook, K.L., \& Evenson, D.P. (2004). Sperm chromatin structure assay (SCSA) parameters are related to fertilization, blastocyst development, and ongoing pregnancy in in vitro fertilization and intracytoplasmic sperm injection $\begin{array}{llll}\text { cycles. Fertility and } & \text { Sterility, } & \text { 1289-1295. }\end{array}$ https://doi.org/10.1016/j.fertnstert.2003.09.063

Wang, M., Sun, J., Wang, L., Gao, X., Lu, X., Wu, Z., \& Wu, Y. (2014). Assessment of density gradient centrifugation (DGC) and sperm chromatin dispersion (SCD) measurements in couples with male factor infertility undergoing ICSI. Journal of Assisted Reproduction and Genetics, 31(12), 1655-1663. https://doi.org/10.1007/s10815-014-0339-4

Wdowiak, A., Bakalchuk, S., \& Bakalchuk, G. (2015). The effect of sperm DNA fragmentation on the dynamics of the embryonic development in intracytoplasmatic sperm injection. Reproductive Biology, 15(2), 94-100. https://doi.org/10.1016/j.repbio.2015.03.003

Wiweko, B., \& Utami, P. (2017). Predictive value of sperm deoxyribonucleic acid (DNA) fragmentation index in male infertility. Basic and Clinical Andrology, 27, 1. https://doi.org/10.1186/s12610-016-0046-3 
World Health Organization (WHO). Department of reproductive health and research. Fifth edition WHO laboratory manual for the examination and processing of human semen; 2010.

Yilmaz, S., Zergeroglu, A.D., Yilmaz, E., Sofuoglu, K., Delikara, N., \& Kutlu, P. (2010). Effects of sperm DNA fragmentation on semen parameters and ICSI outcome determined by an improved SCD test Halosperm. International Journal of Fertility and Sterility, 4, 73.

Zandieh, Z., Vatannejad, A., Doosti, M., Zabihzadeh, S., Haddadi, M., Bajelan, L., \& Amanpour, S. (2018). Comparing reactive oxygen species and DNA fragmentation in semen samples of unexplained infertile and healthy fertile men. Irish Journal of Medical Science, 187(3), 657-662. https://doi.org/10.1007/s11845-017-1708-7

Zeqiraj, A., Beadini, S., Beadini, N., Aliu, H., Gashi, Z., Elezaj, S., Shabani, A. (2018). Male infertility and sperm DNA fragmentation. Open Access Macedonian Journal of Medical Sciences, 6(8), 1342-1345. https://doi.org/10.3889/oamjms.2018.311

Zhang, Z., Zhu, L., Jiang, H., Chen, H., Chen, Y., \& Dai, Y. (2015). Sperm DNA fragmentation index and pregnancy outcome after IVF or ICSI: a meta-analysis. Journal of Assisted Reproduction and Genetics, 32(1), 17-26. https://doi.org/10.1007/s10815-014-0374-1

Zheng, W.W., Song, G., Wang, Q.L., Liu, S.W., Zhu, X.L., Deng, S.-M. \& Tan, Y. (2018). Sperm DNA damage has a negative effect on early embryonic development following in vitro fertilization. Asian Journal of Andrology, 20(1), 75-79. 656 
FIGURE 1. Bland-Altman plots to illustrate that both analytical techniques, sperm chromatin dispersion test HalospermG2 (SCD, as SDF) versus sperm chromatin structure assay (SCSA, as DFI), were equally effective in measuring sperm DNA

660 fragmentation in semen from patients, partners of couples diagnosed with idiopathic

661 infertility

662

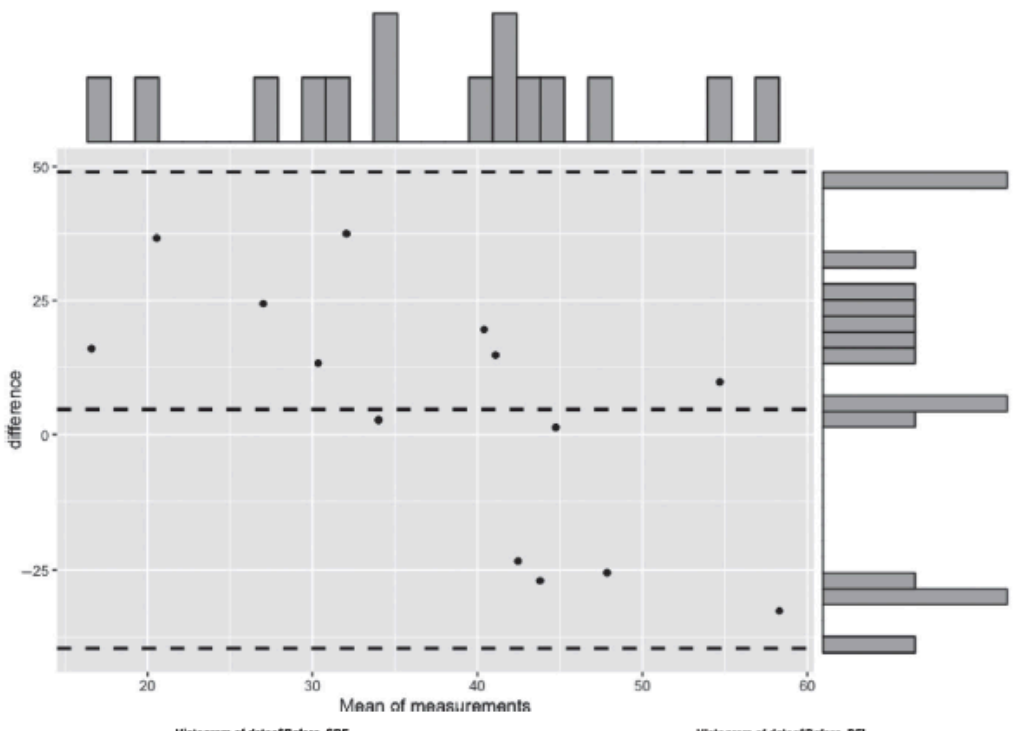

663
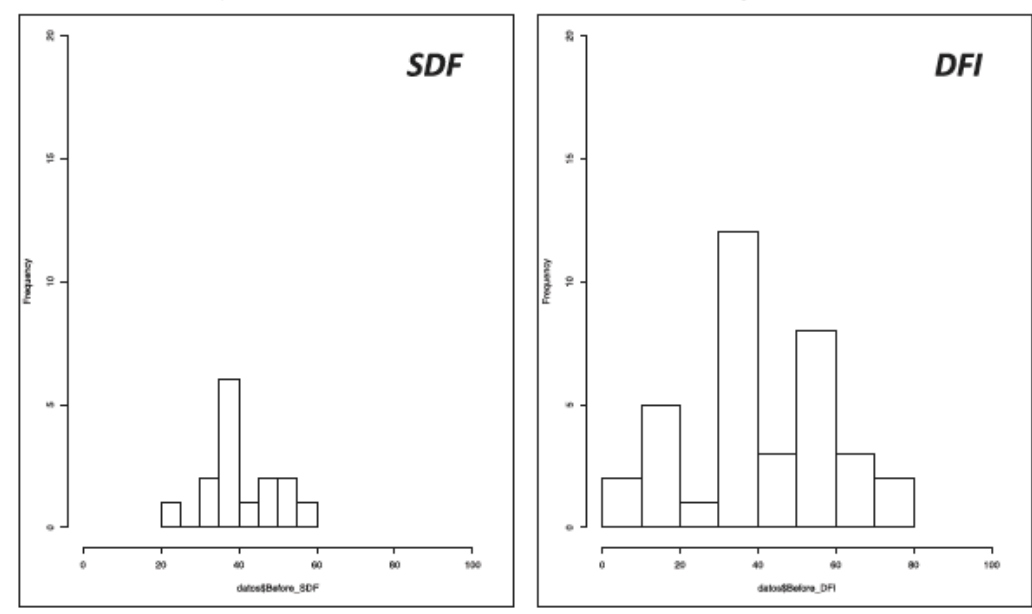